\title{
English orthography: Relation to reading experience*
}

\author{
LESTER A. LEFTON. ANNE B. SPRAGINS \\ and JOHN BYRNES \\ University of South Carloina. Columbia. S. C. 29208
}

Children of first, third, and fifth grade reading levels were presented pseudowords, either first- or fourth-order approximations to English with one item missing. Ss were to guess the name of the missing item. Results showed a clear developmental trend: first-graders show no difference in guessing accuracy between the different orders of approximation. Third and fifth graders show a difference in accuracy between the orders of approximation. An interaction of Order of Approximation by Left-Right Accuracy was found only for the third and fifth graders. The results were interpreted to provide support for the notion that Ss will use the sequential constraints of English orthography whenever they are evident, provided that they have had sufficient experience with English.

The study of the nature of processing within short-term memory has shown that there exists a familiarity effect in which sequences of letters that are closer to English orthography are recalled with greater accuracy than are random strings (Miller. Bruner. \& Postman. 1954). Mewhort (1966. 1967: Mewhort. Merikle. \& Bryden. 1969) has shown that this effect of familiarity of the pseudowords is due to the nature of the transfer of information into short-term memory. He has most recently argued (Mewhort \& Cornett. 1972) that there are two familiarity effects-one involved in the transfer of information from the icon into short-term memory and one in short-term memory itself.

The familiarity effect is not due to mere guessing (Mewhort. 1970). Mewhort showed adult Ss eight-item pseudowords. varying in order of approximation to English. and asked them to guess a missing item. With seven of eight items available. and thus a maximum of context. Ss were able to report correctly $2.3 \% 6.8 \%$ $13.1 \%$ and $18.8 \%$ for zero-. first. second- and fourth-order approximations. respectively. Mewhort then made calculations to show that the effect of guessing could account for only a small part of the familiarity effect.

Lefton (1973) has recently replicated the results reported by Mewhort (1970) and has shown that the duration of the stimulus presentation is irrelevant. More importantly. however. he showed an interaction of the order of approximation of the stimulus and letter position-higher order approximations showed greater accuracy on the right-hand side of the stimulus than did

\footnotetext{
* Partial support for this research comes from a grant from the Vational Institute of Education (NE-G-00-3-0017). We thank Fred Rogers. Principal of the Lonnie B. Nelson School. Columbia. S.C.. who allowed us the use of his facilities. and the teachers of the school. who were patient while we took students from their classes. Ralph $\mathrm{N}$. Haber sponsors this paper and takes full editorial responsibility for it.
}

zero- or first-order approximations. Lefton argued that the sequential constraints of English that are provided by a fourth-order approximation create this interaction since fourth-order approximations are more constrained on the right of a stimulus and thus Ss are better able to guess the names of missing items.

The results reported by Lefton (1973) are consistent with general conceptions of the nature of the use of English orthography. A logical prediction based on these results would be that the extent of an individual's experience with English should, in large part. determine the nature of the obtained results. Children with varying amounts of formal training with English provide a concise test of this prediction. It was hypothesized that children with more formal training with English would be able to guess missing items with greater accuracy than children with less formal training. It was also hypothesized that an interaction of Order of Approximation by Left-Right Accuracy would develop as the extent of formal training increases. To test these hypotheses. children of three training levels were presented with pseudowords with an item missing and asked to guess its name.

\section{METHOD \\ Subjects}

Three groups. each with 10 children. were used as Ss. The mean chronological age for each group was 6 years 11 months. 9 vears 5 months, and 10 vears 4 months. The children were chosen from first. third. and fifth grade levels of the Lonnie B. Velson school. Columbia. S.C. All children knew the English alphabet and had no diagnosed emotional or reading difficulties. The reading level of each child was at his grade level or above. as assessed by teacher judgment on performance on a basic reader and by performance on the Wisconsin Design Word Attack Skills test.

\section{Stimuli}

The stimuli were seven-item pseudowords chosen from the lists provided by Hirata \& Bryden (1971). They were either first-order approximations or fourth-order approximations to English. The stimuli were prepared by placing black letters (Lettraset letters. No. 108) in the center of white cards. $10 \times$ $15 \mathrm{~cm}$ : the width of seven letters was $5 \mathrm{~cm}$. These were the same stimuli used by Lefton (1973). On each stimulus card. one of the seven letters was replaced with a dash

\section{Procedure}

Each of the three groups of children were shown the same stimuli. There were 2 orders of approximation and 7 stimulus positions: these 14 conditions were arranged in a random order and replicated seven times. The first block of trials was considered practice. the remaining 84 trials were included in data analy sis. Fach $\mathrm{S}$ was shown a stimulus card by the $\mathrm{E}$ and instructed to guess the name of the letter he felt would belong in the pseudoword. Ss were allowed to view the stimulus card for as long as they desired. The 1 recorded the Ss response and then turned over the stimulus card and held up another. A testing session lasted approximately $30 \mathrm{~min}$.

\section{The number of correctly reported items was}




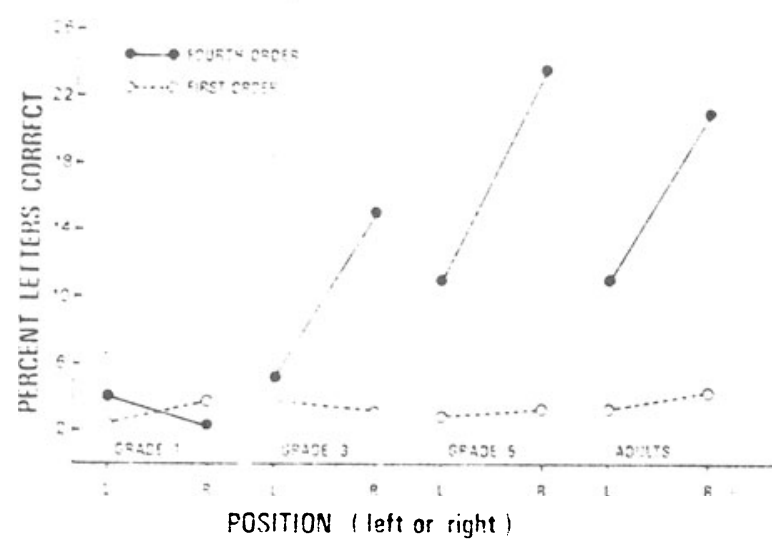

Fig. 1. The percentage of letters reported correctly is presented for each grade level for each order of approximation. The first three positions of the pseudowords were collapsed. as were the last three positions. thus. on the absicissa, left is compared with right for each grade level. Also plotted are the results reported by Lefton (1973) for adults. These data were computed in the same manner and are collapsed across the duration of the stimulus presentation.

computed for each experimental condition for each $\mathrm{S}$ and entered into an analysis of variance. with main variables of grade level (3), order of approximation (2), left-right of the middle letter (2), and Ss in each grade level. The main effects and interactions of the experiment were all very clear, as is presented in Fig. 1. There were strong effects of grade level. $F(2.27)=11.0$, $\mathrm{p}<.001$, of the order of approximation of the stimulus array, $F(1.27)=51.4 . p<.001$. and of the left compared with the right side of the array. $F(1.27)=$ 14.2. $\mathrm{p}<.001$. The two-way interactions also proved significant: Grade by Order of Approximation. F(2.27) $=$ 18.0. $p<.001$ : Grade by Left - Right, $F(2.27)=4.3$, $\mathrm{p}<.05$ : and Order of Approximation by Left-Right. $F(1.27)=30.2 . p<.001$. The three-way interaction of Grade by Order of Approximation by Left-Right was only marginally significant, $F(2,27)=3.0 \mathrm{p} \approx .06$.

\section{DISCUSSION}

The predictions of the study to be tested were (1) that children with more formal training in English would show greater accuracy for fourth-order approximation to English than for first-order approximations with respect to guessing. and (2) that an interaction of Order of Approximation by Left-Right Accuracy would develop with an increase in formal training. The data are most dramatic, bearing out each of the hypotheses.
Children at Grade 1 level with relatively little formal training are not able to make better guesses as to missing items from fourth-order approximation relative to first-order approximations-accuracy levels are very low. about 3 . overall. and reflect the children's lack of experience with English orthography. By contrast. third grade children show a dramatic increase in accuracy for fourth- compared with first-order approximations, and fifth grade children show still greater accuracy. The accuracy levels for the first-order approximation for all levels remain very low. For comparison, the results of the study reported by Lefton (1973) are presented. The results are almost identical to those of the fifth grade children and suggest that. by fifth grade. children can use the sequential constraints of English as adults do. The interaction of Order of Approximation by Left-Right Accuracy found by Lefton has been replicated with older children. and as predicted. a developmental trend was found with an increasing size with more formal training in English.

The present results are most reasonable. considering the extent of an individual's knowledge of English orthography. Both children and adults show low levels of accuracy with first-order approximations to English. Here. there are no sequential constraints of English and each letter is independent of the next. There should be no left-right effect and accuracy should be very low. By contrast, fourth-order approximations of seven items with only one item missing provide a great deal of context and accuracy should increase for individuals with knowledge of English or thography. Accuracy should be even greater on the right-hand side of fourth-order approximations since fourth-order approximations are more constrained on the right of an array than on the left-hand side. In summary. the present results show evidence of a developmental trend in the ability of readers of English to use the sequential constraints provided by English orthography.

\section{REFERENCES}

Hirata, K. \& Bryden, M. P. Tables of letter sequences varving in order of approximation to English. Psvchonomic Science. $1971,25.322-324$

Lefton. L. A. Guessing and the order of approximation effect. Journal of Experimental Psychology. 1973, in press.

Mewhort. D. J. K. Sequential redundancy and letter spacing as determinants of tachistoscopic recognition. Canadian Journal of Psychology, 1966, 20,435-444.

Mewhort. D. J. K. Familiarity of letter sequences. response uncertainty and the tachistoscopic recognition experiment. Canadian Journal of Psychology, 1967, 21, 309-321.

Mewhort, D. J. K. Guessing and the order-of-approximation effect. American Journal of Psychology $1970,83,439-442$.

Mewhort, D. J. K., \& Cornett, S. Scanning and familiarity effect in tachistoscopic recognition. Canadian Journal of Psychology, 1972, 26. 181-189.

Mewhort, D. J. K., Merikle, P. M., \& Bryden, M. P. On the transfer from iconic to short-term memory. Journal of Experimental Psychology, 1969, 81, 89-94

Miller, G. A., Bruner, J. S., \& Postman, L. Familiarity of letter sequences and tachistoscopic identification. Journal of General Psychology, 1954, 50, 129-139.

(Received for publication July 23. 1973.) 